\title{
Body image in brace treated and untreated patients: preliminary results from BrAIST
}

\author{
Traci Schwieger*, Shelly Campo, Stuart Weinstein, William Clarke, Briana Woods-Jaeger, Kelli Steuber \\ From 11th International Conference on Conservative Management of Spinal Deformities - SOSORT 2014 \\ Annual Meeting \\ Wiesbaden, Germany. 8-10 May 2014
}

\section{Background}

There is no consensus regarding the effect of brace treatment on body image in adolescents with adolescent idiopathic scoliosis (AIS).

\section{Aim}

The aim of this study is to compare self-body image, ideal-body image, and self-ideal body image discrepancy, between brace treated and untreated subjects over time.

\section{Methods}

Data from 178 BrAIST subjects that chose treatment were used. Subjects that switched treatment during the study were not included in the analyses. Body image constructs, based on cognitive-behavioral perspectives (1), were used to measure the following: how adolescents' 1) think they look (self-body image), 2) want to look (ideal-body image), and 3) the difference between these constructs (self-ideal body image discrepancy). The Spinal Appearance Questionnaire (SAQ) (2) measures these constructs and scores were compared with largest curve size, BMI, and qualityof-life measures. Wilcoxon ranked sum tests were conducted to test differences in self-body image means, idealbody image means, and self-ideal body image discrepancy means between the treated and untreated groups at baseline and at $6,12,18$, and 24 month follow-up visits.

\section{Results}

At baseline, there were no differences between subjects in the brace group $(\mathrm{n}=118)$ and in the observation group $(n=60)$ regarding age, BMI, largest Cobb angle, and quality-of-life. There were no differences at baseline or at any follow-up visit between brace treated and untreated subjects regarding self-body image, ideal-body image, and self-ideal body image. Results from within group analyses found no significant differences within treated or within untreated subjects between baseline body image scores and 24 month body image scores. In addition, there were no significant differences between body image baseline scores and 24 month scores within subjects having $<6^{\circ}$ degree increase or within subjects having $a \geq 6 \circ$ increase in largest Cobb angle.

\section{Conclusions}

This study does not support findings from previous research indicating that wearing a brace has a negative impact on body image. At baseline and follow-up visits, this study found no difference in body image between brace treated and untreated adolescents. In addition, this study found that body image was not impacted after 24 months of brace treatment.

Published: 4 December 2014

doi:10.1186/1748-7161-9-S1-076

Cite this article as: Schwieger et al:: Body image in brace treated and untreated patients: preliminary results from BrAIST. Scoliosis 20149 (Suppl 1):076.

The University of lowa, lowa City, lowa, USA 